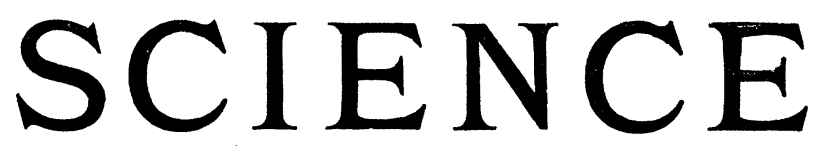

A WEEKLY JOURNAL DEVOTED TO THE ADVANCEMENT OF SCIENCE, PUBLISHING THE OFFICIAL NOTICES AND PROCEEDINGS OF THE AMERICAN ASSOCIATION FOR THE ADVANCEMENT OF SCIENCE.

Editorial Committee : S. Newcomb, Mathematics; R. S. Woodward, Mechanics ; E. C. Pickering, Astronomy ; T. C. Mendenhall, Physics ; R. H. Thurston, Engineering ; Ira Remsen, Chemistry ;

Charles D. Walcott, Geology ; W. M. Davis, Physiography ; Henry F. Osborn, Paleon-

tology ; W. K. Brooks, C. Hart Merriam, Zoology ; S. H. Scudder, Entomology ; C. E.

Bessey, N. I. Britton, Botany ; C. S. Minot, Embryology, Histology ; H. P. BowDItch, Physiology ; J. S. Billings, Hygiene ; Wrlliam H. Welch, Pathology ; J. McKken Cattell, Psyohology ; J. W. Powkll, Anthropology.

Friday, September 12, 1902.

CONTENTS:

Scientific Research-the Art of Revelation and of Prophecy: Professor R. H. ThursTON ....................... 401

On Some Recent Advances in the Fireproofing Treatment of Wood: SAMUEL P. SADT-

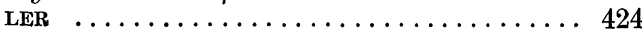

American Association for the Advancement of Science:-

Twentieth Annual Report of the Committee on Indexing Chemical Literature.......

Scientific Books:-

Jahrbuch der Chemie: E. T. ALLEN. Kükenthal's Leitfaden für das zoologische Praktikum: Professor Henry F. NaCH-

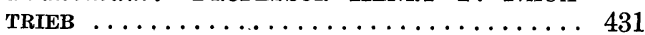

Scientific Journals and Articles......... 431

Discussion and Correspondence:-

'Effective Forces': Professor L. M. HosKINs. Reference Books in Nomenclature: HenRy E. Baum................. 432

Shorter Articles:-

The Physiology of Sea Water: RoDNEy H. True. Bertiella, New Name for the Cestode Genus Berthia Blanchard: DR. CH. WARDell Stules and Albert Hassall. Notes on Canker and Black-rot: P. J. O'GARA.. 433

Paleontological Notes:-

The Generic Name Omosaurus; A New Generic Name for Stegosaurus Marshi: F. A. Lucas ................... 435

Anthropology in America............. 436

Forestry in the Hawaiian Islands........ 436

Scientific Notes and News.............. 437

University and Educational News........ 440

MSS. intended for publication and books, etc., intended for review should be sent to the responsible editor, Professor J. McKeen Cattell, Garrison-on-Hudson, N. Y.

\section{SCIENTIFIC RESEARCH: THE ART OF REVELATION AND OF PROPHECY.*}

I.

ScIENTIFIC research is the highest work undertaken by the man of science, and it can be undertaken with confidence only by him who has made himself familiar with the state of his art, to date, or by the genius whose inspiration may, now and then, make learning, for the time and the occasion, less essential. Yet it is particularly true, in science, that genius involves a talent for hard work. That talent first achieves learning, then seeks further knowledge through research, skillfully interrogating Nature.

Scientific research may be defined as 'the Art of Revelation and of Prophecy.' By investigation, commonly experimental, the research is directed toward the acquirement of new facts in a field in which, at the moment, earlier gleaners either have done little or, having explored the field extensively, yet lack knowledge of certain fundamental elements of the problem of formulation of the laws relating to its phenomena. It is sought to reveal a new system of scientific phenomena, of natural science, or to complete the partly developed theory. When the facts are thus learned,

* An address delivered before the Pennsylvania Chapter of Sigma Xi, by Robert H. Thurston, Philadelphia, June 14, 1902. 
they are studied in their mutual relations and, those relations being ascertained, the law underlying them may be identified. When that law is determined, and in such manner as to make it possible to formulate it, verbally, perhaps algebraically or graphically, its general operation may become discoverable and its action may often be traced backward into an indefinitely extended past and even forward into an equally unlimited future. Revelation and prophecy are thus fruits of science. It may perhaps be said, with truth and literally, that we to-day know no other method of either revelation or prophecy.

It is thus that Leverrier and Adams prophesied the discovery of an outer planet previously unseen. Thus the statistician, observing the growth of a population, or the development of industry during earlier years, predicts the filling of the valley of the Mississippi with a teeming population or the transfer of the financial center of the world into a new metropolis. Darwin revealed a past world history and Laplace indicated the process of organization of a universe. Lodge showed the way to communicate through the intermediate space over an indefinite distance and Marconi and Slaby have talked across a state or an ocean without tangible connections. Rumford and Davy revealed the transmutation of energies, and Morse and Watt and Bell and their fellow-physicists produced national and international systems of utilization and transformation, giving us the steam-engine, the telegraph, the telephone, the electric light and the electric railroad. Hertz and Roentgen introduced us into a new department of energy-transmission in which light penetrates the opaque, and Daguerre gave us an art which permits exact picturing of our surroundings and enables even invisible stars or nebulæ to imprint their portraits upon the photographic plate, and previously unknown worlds thus to reveal themselves.
Lyell, Hugh Miller, and the later geologists gave us our knowledge of the past history of the globe and a prophecy regarding its future; while the astronomer watching the developments in Perseus now sees and describes to us the destruction of the world, 'of which the heavens are seen to melt with fervent heat,' and the simultaneous beginning of the new heaven and the new world, the process and the sequence prophesied alike by Laplace and the inspired seer.

When it was discovered that the brain was capable of being marked off into definite and located sections, each of which related itself to a defined process or, function, it became possible to predict that the surgeon might thus determine the point at which to operate, the place at which a tumor might be found; ultimately, perhaps, finding safe ways of excision, of promotion of healthy growths or of reproduction of degenerated tissue. When, after scientific investigation, the bacteriologists showed the physician how to look for a cause of dangerous diseases and of world-devastating plagues, it became evident that a method of remedy could be intelligently sought through 'research.' Thus the revelation of that extraordinary action of microscopic forms of vegetable life had, as its almost axiomatic corollary, the prophecy of control, if not of entire extinction, of the most vicious and intimidating and fatal diseases, and of relief from the scourges of diphtheria, malaria and yellow fever and even from consumption and intestinal poisons. The previous triumphs of Lister and his colleagues in rendering internal surgery safe and successful were but the forerunners of other triumphs in every branch of medicine and surgery. When the action of alcohol upon the tissues was scientifically demonstrated, and it was assigned its proper place in the pharmacopœia with coffee, tea and other substances of its class, the revelation of its true action, value and 
functions permitted the prophecy that it would cease to be employed under governmental sanction for improper uses, and that, ultimately, the definition of temperance would be scientifically obtained and that the cause of good morals and good manners would be thus everywhere promoted.

That mightiest of seers and prophets, Darwin, has taught us the art of revelation and of prophecy in every field of scientific development. His study of the origin of species first compelled a recognition of the facts that all life and all movement at the moment is but the exhibition, at the instant of observation, at a single minutest point in its path, of the present stage in a constant progression, dating back to an infinite past and to continue into an infinite future. The present is but the infinitesimal in time dividing the past from the future into which the past continuously flows. Darwin called attention to an obvious fact, at once recognized, that there is no solution in the continuity of natural phenomena, whatever may be the catastrophe affecting an atom, a body, an individual or a country or a nation. Every existing noumenon, in whatever realm of nature, in whatever universe, seen or unseen, has a life-history extending continuously and with defined sequence to the farthest past; it may be assumed that its later life-history will be developed, in whole or in elementary parts, by a no less absolute continuity and a no less perfect sequence, into an indefinite if not infinite future.

This is now seen to mean that the universes, all the universes, will continue to evolve their infinite forces and forms, and that energies will continue to exhibit their protean characteristics and to construct worlds, life, nature, art, minds, industries, with constant evolutions of sequence and the revelation of a lengthening curve of progress that shall at every instant point along a terminal; the direction of the momentary tendency revealing a future by its past.

Mendeléef, with his table of the chemical elements arranged in series and in groups, illustrates the possibilities of prophecy in an interesting and striking manner. Classifying the known elements, he discovered the law which controls their relations of atomic weight and predicted that the missing figures, 44, 69 and 72, would later be found to attach themselves to the atoms of elements yet to be discovered. Scandium, gallium and germanium were later found in accordance with his prophecy, much as computed elements of missing planets of our solar system were the sources of the discovery of previously unknown heavenly bodies. Mendeléef, Adams and Leverrier were prophets of the same high order. It may now be anticipated that similar researches, prompted by the discovery of the divisibility of the formerly supposed indivisible atom, may reveal a new order of elementary matter, and revelation and prophecy combine to open to the chemist and the physicist a new world and a new universe. There still remain other as yet undiscovered elements in the "Table of the Periodic System' of Mendeléef, and possibly new orders and new series as yet unpredicted may remain to be revealed by the researches of later. men of genius of this type. Every new element possesses new and peculiar properties and each new discovery gives rise to unique possibilities, both in the use of the new element and in its compounds. Scientific research still has here wonderful opportunities and the fortunate author of new revelations will achieve, not only fame hardly less than his predecessors, but vastly more important to the truly great mind, also advantage to his fellow-men in ways and to a degree as yet unsuspected by the average mind.

Huxley, greatest among seers and prophets of science since Darwin, nowhere illus- 
trates his quality more perfectly than when insisting, in the great debates of his time, on the necessarily and essentially perfect accordance of all truths and the universal evolution of all the worlds. Truths are always mutually consistent and invariably reinforce each other, without limitation. The truths of science and the truths of religion, of morals, of humanity, can never conflict. Should it appear that an inconsistency exists between what are asserted to be facts of science and what are declared to be truths in theology, it would simply compel the deduction that one or the other, perhaps both, must be wrong; forcing the honest and earnest man to the more complete and detailed study of both, with manifest and inevitable advantage to both and to himself, compelling the reconciliation of both formulations by ascertaining the real facts, the common truth. We daily find ourselves on opposite sides of the shield and most frequently discover, on investigation, that the substance is neither the gold of the one side nor the silver of the other, but something oftentimes more precious than either.

There is as certainly no ground for conflict between those who seek to promote pure science and those who as earnestly and honestly endeavor to advance applied science. The laws of the universe are ours to study and so to utilize as to promote, in highest possible degree, the welfare of our country, our neighbors, our families, ourselves. The revelation of the facts and laws of natural science, the upbuilding of the framework and the filling in of the construction called a science, is a first step and its fortunate discoverers are the pioneers of a large body of later investigators, these, in turn, of a still larger body of men interested in making useful the knowledge thus acquired, in every field. All are needed; each helps the other and all are helpful to the world. We do not discuss the relative importance of heart and stomach to brain and muscle, or of the pendulum to the dial of the clock.

All men gravitate toward their positions of maximum usefulness in this world and no two have precisely the same value or power of achievement or adaptation to place and task. Let each do the best possible in the place and in the work thus coming to each, and a maximum efficiency of production, of utilization, of final accomplishment will be achieved.

The term 'revelation' has an entirely correct signification in this connection. Not the most brilliant genius and brightest mind that ever adorned this world, lacking that scientific knowledge and training which is essential to scientific progress and to the discovery of the great facts of nature and the ascertainment of nature's law; not the meditations of the wisest and most thoughtful mind that ever Buddhist or Brahmin possessed, prolonged through all eons constituting the Hindoo chronological cycle; not the highest inspiration of any sage of ancient or of modern times; not all nor. any of these sources of wisdom could reveal the characteristics of an element, the nature of gravitation or its law, the thermodynamic quantivalence, the simplest fact or the most elementary principle in any science or achieve the fundamental knowledge of its youngest and least experienced novice. It is only science that can give us a true revelation of the nature of phenomena, the essential facts of life and motion, or the real basis of evolutionary changes ; far less could either or all predict the position at a stated time of a distant star, the coming eclipse, the penetrative effect of a shot to be discharged from an as yet unconstructed piece of ordnance, the figures of the next decennial census, the atomic weight of an undiscovered element, or the time of high water at any future time in the harbor of New York, Liverpool 
and Cape Town. It is the literal fact that revelation and prophecy are to-day reserved for science.

The revelation of a single fundamental fact, the discovery of one primary principle, by the intelligent application of a scientific method in research, may supply the firm basis of important and far-reaching prophecy. When Count Rumford revealed the fact of the identity of energies, molecular and mass, the almost axiomatic principle that all energy is simply the product of the weight into a function of velocity, regardless of the magnitude of the mass or the character of the movement, it was the assertion of the intertransformability of all the energies of movement, whether of stars and planets and comets in their, orbits, of a flying shot, of a falling stone, of thermal or electrical vibrations or of chemical combinations, whether of masses, of molecules, of atoms or of the recently announced elements of the atoms, if such there prove to be. That one fact of the identity of the energies permitted the predictions of Carnot, serving, later, as the foundation of a new science. It justified the prophecy of an all-comprehending science of Energetics, as Rankine afterward denominated it, which should serve as the common fundamental basis of all physical, chemical and mechanical sciences; bringing molecular and atomic motions and relations into the same field with those of all telluric masses and of every stellar world, comprehending all phenomena of movement, whether of the ether or of a universe gliding through a greater infinity of space.

\section{II.}

The purposes of scientific research, immediate or ultimate, are the revelation of previously unknown facts and natural phenomena, the diseovery of that qualitative relation amongst them which is recognized as the result of the operation of law, the formulation of the law, and its quantitative connection with the facts and their sequence. The immediate purpose is the discovery of the facts and of the phenomena and their quantitative measurement; the later purpose is their grouping, their orderly arrangement, the expression of the law of such arrangement and of their interaction in the production of phenomena and, finally', the construction of systems of fact and law, quantitatively expressed, such as we designate as the sciences, as, for example, the mathematical and physical sciences, mechanics, thermodynamics, physics and chemistry, geology and astronomy. Ultimately must come the correlation of the sciences.

All this means, first of all, the application of scientific method to the advancement of science itself.* It assumes the planning of a scientific method of advancement of science, of a scientific process of development of each department and of the complex whole which constitutes a pantology, the breadth and the depth and the limits of either the larger or the lesser in which no man knows nor perhaps ever can know or conceive.

When knowledge, in greater or in lesser amount, is thus acquired, classified and recorded, the outcome, whatever the intent of its authors, will always be found to be the advancement of humanity in material and, no less, in intellectual and moral ways. In fact, a material foundation is always required for advancement in morals, in manners, in culture and in happiness, by any nation. Education in science, in literature, in language, in the professional basis of a vocation, and in wisdom, learning, culture, morals and religion, is all one.

* "The Scientific Method of Advancement of Science;' Vice-President's address, American Association for the Advancement of Science, St. Louis Meeting, 1878, by R. H. Thurston. 
The fundamental element of the methods of scientific research is the fact, the phenomenon. Facts, individual or in groups, independent or related, are revealed by the investigator and are grouped by the genius, or by the expert in that branch of science. But facts and phenomena are the products of nature's laws and are their expression. A law is the expression of the relation of a group or a series of related facts or phenomena; it is the thread upon which the discovered pearls of truth are strung. It has continuity; the facts themselves are discontinuous, or may be so; the natural world is one great system of phenomena and fact thus bound together, in multiples or in various series, to constitute a single tremendous complex fact.

As I have elsewhere expressed this relationship of fact and laws* "All science is thus made up from the infinite number of facts which are comprehended in the universe of the known and the to-be-known. Its existence is assured by the stability of all those principles of philosophy which are woven into the connecting web. *** The man of science, the philosopher whose task it is to create and to advance all human knowledge of the great kingdom of nature, is therefore a discoverer of facts, an observer of phenomena, a student of nature's laws. He is a systematic recorder of facts, a codifier of laws."

As is now well understood, the 'Law of Substance,' as Haeckel proposed to call it, provides the foundation of the whole code of scientific formulation of natural law. As I expressed it, in the discussion just referred to, "the fundamental principle of the indestructibility of 'the two products of "creation, matter and force, and the fruit of their union, energy,' the principle of the indestructibility of all that has been cre-

* Vice-President's address; Transactions American Association for the Advancement of Science, St. Louis meeting, 1878. ated, supplies a basis for all sciences and for all scientific work.' $*$

'This 'Law of Substance' was thus stated by me at that time (1878) :

"At the basis of the whole science of energetics lies a principle which was enunciated before science had a birthplace or a name.

"All that exists, whether matter or force, and in whatever form, is indestructible except by the infinite power which has created it." +

But the statement of this fundamental and universal law was, in fact, made centuries before and possibly by many wise men of earlier times. Cicero says 'one eternal and immutable law embraces all things and all times,' and he might perfectly well have added: That law is persistence of all the elements of creation.

The purpose of scientific research is thus, immediately and ultimately, the building up of a complete system, or of a section of this great edifice, as the case may be, on the foundation thus established. The work to be done in applied science must always involve the utilization of the work of the scientific investigator in the realms of pure science, and the task of making application of scientific knowledge and of research-revelations, in the promotion of the industrial and higher interests of the people, will be certain of performance when the scientific system is perfected as a code of natural law.

\section{III.}

The fields of scientific research extend into every department of present human knowledge and, probably ultimately, will

*Vice-President's address, American Association for the Advancement of Science, Philadelphia meeting, 1884.

† Transactions American Association for the Advancement of Science, 1878; Vice-President's address on the 'Philosophic Method of Science Advancement.' 
reach into departments still unknown and undreamt of by even scientific men. As engineering is systematizing and correlating all the industries and making even agriculture a branch of chemical and mechanical engineering, so science is gradually coming to comprehend all worlds and it may even be confidently hoped that what have been the speculative philosophics may, in time, become admittedly departments of positive science and subject of fruitful research.

These fields will undoubtedly continue to be simply extensions of the old and longcultivated areas first discovered in the earliest times of which history preserves the records. Astronomy, astrology, the department of alchemistry, mechanics, physics, all the Alexandrian learning, all the later acquisitions of the Saracens and of the later ages in Europe, remain still incomplete as seiences and still afford opportunities of still increasing extent to every investigator. The nineteenth century saw developed the whole thermodynamic theory of the heat-engines and of energy transformation. The improvement of these prime movers-the Archimedean levers which move the world-in their construction and the revelation of the scientific principles of their action, the progress of invention and of science, the sole guide toward perfection, the sole competent judge of approximation to perfection and of the perfect work, through all that century went hand in hand, and once the thermodynamic theory of the engines became fully supplemented by a theory of wastes by extra-thermodynamic processes and by a financial theory of application, the work of Watt and Carnot may be said to have been completed. The commencement of the twentieth century sees the whole theory of the steam-engine practically completed and the structure of the machine, either as a reciprocating engine or as a steam-turbine, substantially perfected; while the engineer is now taking up the gas engine, also a century old, and reducing its theory and its mechanism to similar perfection. Henceforth we must expect exceedingly slow progress in this field and, as the outlook now appears, early and complete interruption-unless, indeed, the inventor and the man of science can find ways of entrance into a new field. And why should they not?

During the nineteenth century the engineer. made steady progress by increasing his steam pressure from one atmosphere to fifteen, and, experimentally, to a hundred atmospheres by increasing piston speeds from 100 to 1,000 feet per minute and by placing his engine-cylinders in series to intercept still unconquered wastes. Now he is still moving forward, though cautiously, in the same lines, and is increasing the thermodynamic temperature-range by superheating steam and the ratio of expansion by adopting the steam-turbine; thus, also, evading the heavy tax of socalled 'cylinder condensation.' External conduction and radiation and friction are minimized and we still gain, though the approximation of the real to the now perfectly defined ideal has come to be fairly close in our best work.* A new path must be sought, and it is for the engineer and man of science together, or both in one, to show us the way.

Among all the problems of the twentieth century, none are more seductive, more glorious in aspect, more fruitful of good to the race, than those assigned the man of science in this field and to his partners, the engineer, the inventor, the mechanician.

* 'Manual of the Steam Engine,' New York, J. Wiley \& Sons, R. H. Thurston. See Chap. VII., Vol. I., for the 'Financial Theory' and Chap. VIII. for a summary of thermodynamic and applied theory of the steam-engine; Chap. VII., Vol. II., for the ultimate commercial outcome of theory and art, conspiring. 
The 'next great problems of science,' as I have called them, involve some which are extraordinarily important and curious, genius-provoking and talent-utilizing : problems which can presumably be only solved through the cooperation of all those forms of native talent, perhaps combined in the one man, perhaps in all-the engineer, or the man of science, or the inventor and the mechanician.

"The progress of the race and the advancement of civilization, whether in the direction of industrial improvement or of intellectual growth, depend, the first mainly, the second largely, upon the extent and the success of man's utilization of the four great natural forces, or 'energies,' as the man of science calls them: heat, light, electricity, mechanical or dynamic power.

"The engineer, to whom is confided this duty of utilizing all the forces of nature for the benefit of his. fellows, has, however, now apparently reached a point beyond which he can see but little opportunity for further improvement, except by slow and toilsome and continually limited progress. $\mathrm{He}$ seems to have come very nearly to the limit of his advance in the directions which have, up to the moment, been so fruitful of result.

"The living body is a machine in which the 'law of Carnot,' which asserts the necessity of waste in every heat-engine, and which shows that waste to be the greater as the range of temperature worked through by the machine is the more restricted, is evaded; it produces electricity without intermediate conversions and losses; it obtains heat without high-temperature combustion, and even, in some cases, light without any sensible heat. In other words, in the vital system of man and of the lower animals, nature shows us the practicability of directly converting one form of energy into another, without those losses and unavoidable wastes characteristic of methods the invention of which has been the pride and the boast of man. Every living creature, man and worm alike, shows him that his great task is but half accomplished; that his grandest inventions are but crudest and most remote imitations; that his best work is wasteful and awkward. Every animate creature is a machine of enormously higher efficiency as a dynamic engine than his most elaborate construction, illustrated in a 10,000 horse-power engine. Every gymnotus living in the mud of a tropical stream puts to shame man's best efforts in the production of electricity; and the minute insect that flashes across his lawn on a summer evening, or the worm that lights his path in the garden, exhibits a system of illumination incomparably superior to his most perfect electric lights."

Here we have a single example of the opening of a new field of research of tremendous importance to the human race, yet unexplored and hardly recognized.

It seems more than probable that it is to the mysteries and lessons of life that the chemist, the physicist, the engineer, must turn in seeking the key that shall unlock the still unrevealed treasures of coming centuries. These constitute nature's challenge to the engineer.

Nature in each of these cases converts the energy of chemical union, probably of low-temperature oxidation, into just that form of energy, whether of mechanical or of a certain exactly defined and required rate of ether vibration, that is best suited to the intended purpose, and without waste in other force, utilizing even the used-up tissue of muscle and nerve for the production of the warmth required to retain the marvelous machine at the temperature of best efficiency, whatever the environment, and exhaling the rejected resultant carbonic acid gas at the same low temperature. Man wastes one fourth of all the heat of his 
fuel as utilized in his steam boiler, and often ninety per cent. as used in his open fire-places; nature, in the animal system, utilizes substantially all. He produces light by candle, oil lamp or electricity, but submits to a loss of from one fifth to more than nine tenths of all his stock of available energy as heat; she, in the glow-worm and fire-fly, produces a lovelier light without waste measurable by our most delicate instruments. He throws aside as loss nine tenths of his potential energy when attempting to develop mechanical power; she is vastly more economical. But in all cases her methods are known to be radically different from his, though as yet obscure. Nature converts available forms of energy into precisely those other forms which are needed for her purposes, in exactly the right quantity, and never wastes, as does invariably the engineer, a large part of the initial stock by the production of energies that she does not want and cannot utilize. She goes directly to her goal. Why should not man? He has but to imitate her processes.

"Should the day ever come when transformations of energy shall be made in nature's order, and when thermo-electric changes shall be a primary step toward electrodynamic application to purposes now universally attained only through the unsatisfactory processes of thermodynamics as illustrated in our wasteful heat-engines, the engineer, following in his work the practice of nature, which has been so successful throughout the life of the animal kingdom, will find it easy to drive his ship across the ocean in three days; will readily concentrate in the space now occupied by the engines of the Majestic a quarter of a million of horse-power; will transfer the millions horse-power of Niagara to New York, Boston, Philadelphia, to be distributed to the mills, shops, houses, for every possible use, furnishing heat, light and power wherever needed." $*$

IV.

Methods of planning scientific investigations involve, first, the precise definition of the problem to be solved; secondly, they include the ascertainment of the 'state of the art,' as the engineer would say, the revision of earlier work in the same and related fields, and the endeavor to bring all available knowledge into relation with the particular case in hand; thirdly, the investigator seeks information which will permit him, if possible, to frame some theory or hypothesis regarding the system into which he proposes to carry his experiment, his studies and his logical work, such as will serve as a guide in directing his work most effectively. The first step is thus the acquirement of a complete knowledge of the essential work of investigation which has been accomplished by others, to date. This eliminates the primary work and permits avoidance of repetition, as well as reveals the suggestions of every great mind which has attacked the question in its preliminary stages, and places the investigation on the level from which further advance becomes directly and effectively practicable. It also gives the proposing investigator a firm and ample foundation on which to build higher and exhibits to him the trend of the work, in advance. He will have ascertained the locus and direction of what I have called a 'curve of progress' and it may give him the needed data from which, if quantitative measures and definite relations are available, to construct the graphic history of the case throughout its earlier periods.

The research may next be undertaken intelligently and with definitely arranged strategic predisposition of detailed plans of operation. The condition of the work

\footnotetext{
* The Forum, R. H. Thurston, September, 1892.
} 
is known to date and the direction of current progress is ascertained. The investigator loses no time or energy in following false leads.

The empirical, the imaginative and even the guess-work systems, or perhaps lack of of system, more accurately speaking, have their place, however, even in scientific research. The work of Copernicus, of Kepler, Newton, even, must be thus classed in important parts.

"The dim Titanic figure of the old monk seems to rear itself out of the dull flats around it, pierces with its head the mists that overshadow them and catches the first glimpse of the rising sun

\section{$6 * *$ * like some iron peak, by the Creator}

Fired with the red glow of the rushing morn." "

But Copernicus first made a shrewd guess and then followed scientific and logical mathematical work and confirmation. This illustrated what Tyndall called 'the scientific use of the imagination'; it was not a scientific beginning.

Kepler, also, was 'strong almost beyond competition in speculative subtlety and innate mathematical perception.' His method of procedure was illustrative of that of 'trial and error' without scientifically established premises or Euclidian sequences. For nineteen years, he guessed at the solution of a sufficiently welldefined problem, finding his speculation erroneous every time, until, at last, a final trial of a last hypothesis gave rise to deductions confirmed by observation and the laws of Kepler were established. His first guess had been that the orbits of the planets were circular, his next that they were oval, his last that they might be elliptical. Only in the latter case could the observed data be reconciled with the assumption of Kepler.

In somewhat similar manner, Galileo sought to prove the correctness of his hy- pothesis regarding gravitation; consistency with which would compel falling bodies, unresisted, to fall at the same rate, whatever their magnitude. He proved this fact by an experiment, taking two iron shot, the one large and the other small, to the top of the Leaning Tower of Pisa and showing that their fall occupied the same time. The 'guinea and feather tube' in which, within a vacuum, the two drop with similar rapidity, is but a refinement of that first experimental confirmation of Galileo's idea.

'The simultaneous clang of those two weights sounded the death-knell of the old system of philosophy and heralded the birth of the new,' not as condemning speculation and guess-work or the 'scientific use of the imagination,' but as enforcing the principle that no hypothesis can be accepted until given raison d'être by an experimental or observational appeal to nature.

Even Newton, witnessing the fall of the apple-an apocryphal but not improbable story-and thus set thinking, necessarily began by speculating upon the probable cause of the phenomenon and its laws. Kepler had shown how the planets moved in their orbits; Galileo had discovered the method of action of gravitation and had revealed the Laws of Motion now adopted by Newton. The time was ripe for another step. Newton conceived the idea that the gravitational force must be universal and must affect every substance throughout space, its laws being without limit, the constants in the formulas expressing them hav'ing the same value. The law of gravity is that of a central force acting throughout space with an intensity varying inversely as the square of the distance from the center of attraction. Newton at once applied his hypothesis to the solar system, and proved that the motions of the planets, as revealed by Copernicus, were consistent with this new ascertained fact. The sun 
was the central attracting body and every planet and each satellite was obedient to this all-controlling force.

Thus, while the correct sequence is, logically, the deduction of Kepler's Laws from the Laws of Gravitation, the fact is that the relation was discovered by scientific use of the imagination and the confirmation by deduction from an assumed accuracy of those primary laws followed.

Newton's estimate of his work, as that of 'a child playing on the seashore' while 'the immense ocean of truth extended itself unexplored' before him, in the light of these considerations seems less remarkable. Newton did indeed play on the shore of the great ocean of truth, and mused and speculated as he played; but he also did what the greatest of the ancient philosophers declined to do-he speculated with the aid of all his reasoning power, and then submitted his deductions to the touchstone of direct test by experiment and by comparison with the facts revealed by research.

Again and later: Lagrange and Laplace discovered and enunciated the two 'Laws of Stability,' the 'Magna Charta of the planetary systems'; but the discovery was brought about by a scientific use of the speculative faculty, and the laws were confirmed by reference to the whole system of gravitational mechanics founded by Galileo and Newton, proved by experiment and confirmed by long years of accurate observation. Laplace's 'Nebular Hypothesis' was a 'sublime speculation.' Its acceptance or rejection is made by every man of science, subject to its confirmation or disproof by direct appeal to fact.

Scientific prophecy, illustrated by the magnificent work of Adams and Leverrier in their computation of the elements of the orbit of Neptune, from the known measures of variation of other planets in their orbits produced by disturbances set up by the unknown planet, is the loftiest of all forms of product of the mind of man. Prediction was a common fact in science at an early date; but it never before häd been the fact that a great mathematical astronomer, in his study, with tabulated figures of irregular motions of heavenly bodies before him, had even attempted to compute the position of that disturber of the harmony of the spheres and to say to the observer at the telescope: 'Direct your glass at the infinitesimal point in all the sky indicated by these computed measures and you shall see a new world.' It was thus, however, that Neptune was found.

\section{V.}

The methods of conduct of experimental research are in general simple and have one common system. The preliminary survey having been made, the work of earlier investigations having been collated and arranged with reference to the purpose in view, and the plan of the work having been in a general way settled, the first step is to determine what apparatus is needed in the prosecution of that plan and what is available. The plan and the aim of the research give the necessary basis of judgment regarding needed apparatus, and it may often happen that it is all obtainable without difficulty or delay. It oftener occurs, however, that old apparatus must be modified to meet the precise requirements of the work in hand, and that, in many cases, entirely new must be devised. Sometimes an important, or, at least quite novel and ingenious, instrument or machine must be invented to meet a special need. 'The plan itself has given opportunity for the exercise of both invention and imagination; the selection, the construction and the assignment to specific work of the apparatus will be found to demand in most cases even more of both these attributes of genius.

The apparatus having been thus selected, 
catalogued and assigned to duty, the plan is revised to make sure that every step in its series of proposed tasks is provided with the needed apparatus and material, direct and accessory. The scheme of the work may then be written out in full, and the memorandum should include a reference to the apparatus selected for use at every successive step and a statement of the kind and quantity of material to be provided. The materiel of the campaign may next be assembled or, if extensive, locatted, and its availability assured. It is sometimes embarrassing to reach an important point in such work and to find that a piece of apparatus or certain material needed, possibly immediately and imperatively, is not to be had. It may be necessary to set about the design and construction of special apparatus at once in order that the investigation shall not be delayed at a later stage by its non-completion.

My own experience yields an illustration of this point. I had been intrusted with the exploration of the whole field of those ternary alloys of most importance in the arts, those of copper, zinc and tin, the 'kalchoids,' as I called them, and could see no way of systematically and economically, yet completely, accomplishing what seemed the impossible task of determining the strength, elasticity, ductility and other properties of the useful alloys in all the infinite number of possible compositions. The task proved simple, easy and inexpensive, comparatively, when I had, after some months of delay awaiting a satisfactory scheme, hit upon the system of planning the representation of the results of researches involving such measurements of three coordinate dimensions.* To-day, the

\footnotetext{
* ' On a Method of Planning Researches involving Three Dimensions,' Transactions of the American Association for the Advancement of Science, 1877. 'Strongest of the Bronzes,' Transactions Am. Soc. C. E., 1881.
}

principal characteristics of that whole class of useful alloys are not only determined, but are represented by graphic and glyptic and algebraic forms permitting their computation or measurement, whatever the alloy sought.

The outcome was also, as obviously might have been prophesied, the identification of what I denominated the 'maximum alloy' - the strongest alloy that man can make by combination of those three metals-its composition, its strength and its every important characteristic. An alloy which has been on the market now for many years and has proved to be of extraordinary value is one of these. 'kalchoids,' closely approximating the 'maximum alloy' in its proportions and properties.

By patiently waiting until a satisfactory system could be adopted, it thus became possible to select intelligently a few representative alloys and by the results of their examinations construct the curve or the surface, the diagram or the model, of which the ordinates should give the values of the characteristic by them measured of all possible alloys of the metals employed, whether the alloy be binary or ternary.*

One of the best illustrations of the scientific method of planning the investigation of an as yet unexplored field, and of the endeavor to discover a method of utilization of as yet undiscovered means of obtaining a desirable and defined result, is the case of the invention of the new general method of production of aluminium.

The investigator was an undergraduate student at Oberlin. He recognized the probable value of aluminium in the arts, could it be produced in large quantity for market and at a low cost. He believed that electrolysis would prove the most convenient, perfect and inexpensive method;

* Graphic Diagrams and Glyptic Models'; R. H. Thurston, Transactions As. M. E., Vol. XIX., 1898. 
but there was at the time no known process by which it could be applied to this element. The problem as enunciated by the investigator was this: To find a form of electrolyte rich in aluminium which should be comparatively easily separated into its elements, and to discover a substance for the solvent which should prove a satisfactory 'bath.' To meet the requirements of the case, this latter substance must be a good conductor, of electricity, must readily dissolve the proposed electrolyte and must have a higher resistance to electrolytic disruption than the electrolyte. This was the scientific statement of the fundamental facts to be brought into use, and, these requirements being met, it was obvious that, if the current should not prove too expensive, the process would unquestionably produce the then rare and costly metal at a remarkably low cost.

To discover, the needed substances for electrolyte and solvent was a problem of a different sort; it involved the examination of all available compounds of aluminium, so far as obviously not suitable, the study of the various possible solvents for the compound selected and the determination of electric conductivities-a series of solutions of problems by 'trial and error.' By virtue of rare familiarity with the chemistry and the physics of the subject, the search was, after a time, rewarded by complete success. It was discovered that beauxite - the oxide of aluminium, alumina, in fact-is dissolved by molten cryolite, the double silicate of aluminium and sodium, and that the latter, while dissolving the former freely and serving as an ideal solvent, also itself broke up under the action of the electric current at a much higher voltage than alumina. So far as known, these are the only substances in nature which stand to each other in such relations as to permit commercial production of the metal, and Charles M. Hall, the inventor of the process which now practically gives to the world its whole annual product of thousands of tons of aluminium, was at once inventor, discoverer and scientific and successful investigator. The incident of the discovery of a method of production of a new commercial metal for employment in the useful arts in enormous and rapidly increasing quantity thus illustrates the characteristic element of each of the great departments of research.

The instrumentalities of successful research are essentially three, genius, apparatus, organization; yet valuable work may be done, where the problem is simple and definite, by the steady worker, well-informed, intelligent and industrious, even though not a genius. The first and highest class of work is illustrated by that of a Davy, a Faraday or a Rowland or a Rankine; the second is daily exemplified by the investigations of the engineer, the metallurgist, the industrial chemist or even by the average business man collecting facts relating to his vocation and reducing to practical application the results of ordinary every-day investigations of the state of the market, the condition of the crops, or the accumulated stocks of the trade. The now common method of graphical record of the course of prices, wages and production permits every business man to discover the trend of change and the probable values of the immediate future. This is as truly research as is much of the scientific work of the chemist, the physicist or the astronomer.

Yet, for successful revelation of the previously mysterious secrets of nature, the highest genius, the most complete equipment for investigation and the perfect organization of a staff must often be made to conspire.

The provision of extensive organizations for the special work of research is now coming to be an established and recognized 
modern method of systematic attack upon the still unrevealed treasures of the natural world, and the foundation of associations and the provision of large capital for the work of research are the most recent instrumentalities. The Royal Institution of Great Britain, built up by the great American, Count Rumford, the Smithsonian Institution, established in the United States by a famous Englishman, and the Carnegie Institution, now just founded by the greatest of organizers, a Scotch American, are illustrations of the latest and greatest of modern systems of deliberate preparation for, and of systematic prosecution of, scientific promotion of the advancement of science.

\section{VI.}

Results obtained, whether in the immediate work of solution of the problem in hand or incidentally and as bearing upon other more or less related questions, should be very carefully and systematically collated, systematized with reference to their respective relations to the problem, and, where practicable, tabulated in such manner as will permit their convenient use at all times and for any purpose. The data and the results of investigation will thus be brought into natural relations and propinquity, and the whole outcome of the work thus brought into relief and given available form for study.

It will often be found possible to employ the figures thus obtained in the identification of constants in already known rational equations forming part of the previously constructed theory of the case, or in empirical expressions improvised for the occasion. Wherever numerical and mathematical relations can be identified and expressed, and even when analysis does not lend itself readily to the work, it will often be found practicable to express the law relating new data and new facts to one another and to the already established sys- tem, so far as complete, by graphical methods. In fact, for many, if not for most, purposes, it is much easier to comprehend and to employ a law exhibited by lines and curves than when it is stated algebraically. Many problems which are difficult, if not impracticable, of solution by algebraic analysis, may be readily, conveniently and fruitfully solved graphically.

Wherever practicable, the rational expression of the law is far. preferable to the approximate and the empirical formula representing the relation of data obtained experimentally, and without reference to the underlying law; yet it often happens that the first, and in fact only practicable, system is that of plotting curves on 'squared paper,' 'section paper,' and obtaining their equations as the algebraic representation of relations and sequence. This was done by Regnault in constructing his still standard and classic 'steam-tables.'

The laboratory for research, devoted especially to that work, equipped with every known device for weighing, for measuring, and for recording data, furnished with a staff of trained and scientifically learned men, directed by one supreme directing mind, is the latest and greatest of mechanisms for working those inexhaustible mines in all departments of science. But the laboratory for research, however well equipped and manned, must usually have its special field, and many laboratories must be employed in the development of the innumerable lines of scientific research already opened and partially explored. Any one organization must invariably find itself drawn by a sort of grativation into some special field, and specialization is as natural, and as necessary, in fact, in research as in any other business. The laboratory of one great investigator becomes absorbed in the study of the coal-tar. products; that of another in the investigation of the conductibility and 
non-conductibility of various substances and in their employment in the transmission-systems of electric light and power 'plants'; still another is given up largely to the examination of the properties of the materials of construction and to tests of columns and beams of steel and iron. There must thus be many laboratories, and no one institution, however well endowed, can hope to cover the whole realm of science.

So it happens that there is room and opportunity for all, and the laboratories directed by a single administration, as of the Royal Institution of Great Britain, may direct their energies under the eye of a Dewar toward the discovery of the properties of the gases near the absolute zero and to the determination of the temperature of the interstellar spaces; while another, a more widely extended, field may be covered, as by the Smithsonian Institution, under a Langley, supervising and aiding effectively the extension of human knowledge in all departments of science by publication, by exchanging the papers of men of science and transactions of learned societies throughout the world, at the same time prosecuting research-work in important fields. Still another method may be illustrated by a Carnegie Institution, with its center of action fixed at the capital of the nation, reaching out into every corner of the land and promoting research in every laboratory in which a competent expert and a genius of sufficient caliber may appear. It provides this investigator with apparatus, lifts that famous inventor or discoverer out of the depths of routine and sets him free to carry on his glorious enterprise at his own sweet will, rising to the full height of his potentiality while discovering and utilizing already initiated researches of previously unknown and perhaps otherwise never-to-be-known men of genius. It provides apparatus and funds to enable such men to carry investigations to ultimate, fruitful and important ends.

There is room and there is need for all these, and for every other device for the acquisition of knowledge that may be conceived by the mind of man. Nature is infinite in her variety and in character of manifestation, and the universes are boundless in microcosm as in macrocosm. No laboratory, no investigator, nor any number or combination of laboratories, in the hands of however many men of superlative genius for research, can ever exhaust either of these still unimagined fields or reach the end of discovery of new realms; nor. can any amount of capital appropriated to the promotion of research in pure and applied science ever bring about a state of affairs analogous to that of an industry outreaching the market by its overproduction. There will never be overproduction either of men of genius or of contributions to human knowledge, or to the comforts, the intelligence or the moral advance of a world like ours, capable of infinite progress.

The laboratories of the colleges and the great universities, the world over, have been the most prolific sources of scientific discovery and revelation. Recently, however, the industrial establishments of the great nations of Europe and of the United States have discovered that it is greatly to their advantage to prosecute such investigations for themselves in their own special fields of work. The German chemists and the electricians of the United States, and in this country also, the faculties of the engineering schools, perhaps more than any other departments, have been thus engaged in the promotion of the industrial movements of their respective countries.

Planning a curriculum for engineering schools in 1871, my conviction was so strong that the advancement of the applied sciences through systematic and carefully 
planned research must soon come to be a recognized and a most important duty of such schools that I made the laboratory for research a leading feature of the scheme. Gradually its scope and its work have extended until it has ultimately become one of the most fruitful of all the adjuncts of such institutions. To-day, in every engineering school of importance, it is considered no less desirable and necessary to provide for systematic research than for laboratory instruction of students. Progress in the industries is now very greatly promoted by the work of this department of the professional school.

\section{VII.}

Study of the data and results of the investigation, thus collated and placed in a form suitable for convenient and accurate examination and comparison, once the work is complete so far as experiment is concerned, is the final step of the investigation proper. If the object has been the identification of an important datum, as when our old friend, Rowland, measured the relation of mechanical and thermal energy, or as when my former pupil, Michelson, measured the velocity of light, the main work is that of correction of minor errors and of standardization of apparatus. When the purpose is the determination of laws as well as facts, as when my former colleague, Langley, studied the resistances of the air as a problem in aviation, the numerical values must not only be checked and corrected, but the numerical relations of those facts and the law represented must be formulated. The former task involves skill in mechanical construction, the latter talent in the production of a scientific theory; both, when well performed, testify to genius in the investigator.

Formulation, tabulation and systematic presentation for study thus may be so performed as to make the work of survey, of collaboration and of detection of relations of law and of quantivalence comparatively easy. Lacking experience, or talent, or system, the imperfect tabulation of data, the inaccurate representation of relations or the unintelligent grouping and imperfect systematization of quantities by the investigator may conceal rather than reveal the solution of the problem in hand. The best and principal protection against such hindrance is correct and precise formulation of the problem at the start. Where a curve of results can be laid down, or where any graphic or glyptic presentation can be made, it is usually easy to perceive hitherto concealed relations and to secure desired deductions and conclusions. The production of lines and surfaces thus exhibiting these smoothly continuous variations of value also has an exceedingly important use in the detection of individual errors and the establishing of correct figures.

Rumford, Davy, Mayer, Joule and Rowland, thus establishing the measure of the 'mechanical equivalent of heat,' made revelation of a fundamental datum on which, coupled with the principle of the quantivalence of the energies, it became possible to build up a new science which should give prophecy both of paths of progress and of limits of improvement and of efficiency for the heat-engines which have proved of invaluable service to the engineer and, through him, to the world. Carnot, seer and prophet, formulated in outline the new science. Rankine, studying the facts and data and fundamental principle thus revealed, from the standpoint of the engineer; Clausius, as a mathematical physicist making a similar study, the single fact and the single datum, combined with a single law, that of the equivalence of thermal and dynamic energy, enabled them, independently, each to accurately construct the new 
science and to furnish the engineer the guiding principles of construction and operation of all heat-engines. To-day the engineer is following Rankine in the study of all new lines of improvement of efficiency of the heat-motors, and the chemist and the physicist are similarly following the guiding hand of Clausius in tracing the course of modern science in thermodynamic, in electro-dynamic and in electro-chemical branches of energetics. Each great pioneer revealed the processes of treatment of the subject best adapted to his own field of work, and each became a revealer and a prophet, pioneer in revelation and prophecy, in a new world. All contemporary and future workers will follow, confirm and utilize the scientific development of energeties as formulated by these great leaders at the middle of the nineteenth century.

Sir Humphrey Davy, Michael Faraday and their contemporaries and later repétiteurs, gave us that tremendous power in modern industrial development, electrolysis. They revealed the faets and the laws controlling the operation of electrical energy in its action upon ehemical compounds and elements and electro-chemical science, now but a century old, is doing its marvelous work in a thousand ways. It enables new and cheap methods to be employed in the reduction of the oldest of 'useful' metals, copper, at times clogging the market by thousands of tons of surplus; it gives us new elements and new and useful metals, and thousands of tons of aluminium are poured into the marts of trade and uncounted miles of conducting wire utilized in transportation of intelligence. The laws of this new science are now wellestablished and it needs no prophet to foresee that it is to play a wonderful part in the industrial operations and the general progress of the twentieth century.

Electricity, as hand-maiden with steam, through a chain of experimental researches by the later physicists and their utilization by contemporary engineers and electricians, has been made accessory to the primary source of energy in the distribution of that energy to distant points of application; while the efficiency with which this form of energy may be transformed and employed as light gives enormous gains in the economics of out-of-door and in-door lighting. The indications that may now be detected in many directions of still further progress through common methods of scientific development, encourage us to expect, and soon, a multiplication of the amount of illumination which may be obtained by the unit of power thus transformed.

Even beyond this promised perfection of energy-transformation may be dimly, perhaps, but very positively, seen the indications of a probable entrance of the chemist into this field as rival of the physicist and of chemico-dynamic processes to be yet thus utilized.

\section{VIII.}

Facts and law, data and their relations, phenomena and the sciences, are always paired, and the study of the one element of the pair involves at least the recognition of the other. The natural and commonly inevitable order in research is the discovery of new facts, their correlation with those already known, the revelation of the relations of magnitude of their quantities, the anticipation, the prophecy, often, of the underlying and connecting law, the statement of that law qualitatively, the final identification of the numerical values of the terms in which the law is expressed, and the precise statement of principles in quantitative terms.

This statement of law within its limited range becomes, in turn, a newly revealed fact of nature and of the science attacked 
by the investigator, and it, in turn also, is next studied, in its relations to other similarly circumscribed laws, with a view to further combinations and extension; and thus gradually a science is built up. This process is well illustrated by the work of Rankine and of Clausius in the construction of the modern science of thermodynamics. The earlier work of Carnot as well illustrates the different work, the radically different work, the radically different methods, of the investigator conducting a research in his study on the simple basis of an ascertained principle or a broad and probable assumption. The one investigation results in the construction of a science upon two fundamental principles, revealed by a series of experimental studies extending from the time of Rumford to the time of Joule and the builders of the science; the other is a logical construction based upon an assumed, but later fully revised and substantially confirmed, principle; which being admitted, the series of deductions follow as directly, as definitely and as certainly, as the propositions of Euclid, once the axioms are recognized.*

The spectroscope and the telescope cooperate in the revelation of facts and data of singular interest and importance in astronomy; permitting, often, the prediction of a future likely to embrace hundreds of thousands of years. They determine the number, the periods and the magnitudes of visible stars, and through the revelation of their movements lead to the detection, and even the weighing, of invisible companions. It is not inconceivable that predetermination of the location, orbit and direction and velocity of the stars may ultimately lead to the prediction of events of enormous importance. The occasional sudden appearance of

\footnotetext{
* Compare Rankine's 'Manual of the Steam Engine' with Clausius's 'Mechanical Equivalent of Heat,' and both with Carnot's 'Reflections on the Motive Power of Heat.'
}

new stars lends at least some confirmation to the idea of Haeckel that the renewal of kinetic stores of energy throughout the universe, and throughout all time, may be a result of collision of masses moving across the fields of travel of other heavenly bodies, causing by their inconceivable and immeasurable impacts increase of temperature and such reconstruction of systems as at once accounts for the appearance of the new stars and the reconstitution of universes. The new star. in Perseus very possibly thus illustrates this renewal of long latent and potential energy and the possibly eternal life of the universe in its essentials as we now know it.

When sufficient data have been revealed by these wonderful instruments, it may be found that some 'runaway star' is directing its course toward our own solar system and threatening the extinction of existing. life and the rebirth of a new system, with renewed evolutions from a new beginning. There is nothing inconceivable in the notion that at some future time, science may thus predict the impending catastrophe and the time when 'the heavens shall melt with fervent heat,' confirming an old, and giving a new and more exact, revelation. When the exact direction, distance, course and velocity of ' 1830 Goombridge' shall have been thus ascertained, it may possibly give us intelligence of a coming catastrophe among distant worlds more astounding and awe-inspiring than was ever before conceived by the mind of man, thus predicted by contemporary science and perhaps actually illustrated by many an earlier worldcollision, as by that impact, beyond measure of our understanding, which has but just now produced Nova Perseus and its fast-forming new nebula. Such a worldhistory would exhibit a cycle in which but one instant is catastrophic and of which the complete tracing measures an eternity. A series of such eternities, of infinite num- 
ber, would be implied as the chronology of one universe, in which chronology, to its historian, a day is as a thousand years and a thousand years is but a day. The course of the 'flying star,' 61 Cygni, or the inconceivably rapid flight of the runaway star, measuring off two hundred miles each second, as it speeds across our universe and perhaps toward another' in the unknown depths of space, when thus viewed, becomes only an incident in the infinitely great. The life and movements of the gnat or of the minutest bacillus affords hardly less attractive and impressing studies of the microcosm.

The known and weighed and measured, but never yet seen, companion of Procyon may yet be found, as has been already the similar companion of Sirius, and, found, may illustrate a phase in the life-history of the worlds as instructive, as impressive, as suggestive, as either of these other phenomena of the heavens; but all, near or far, microcosmic or macrocosmic, simple or mysterious and complex, all are but parts of one infinite whole, and there exists, though perhaps never to be fully revealed, a larger science which includes and governs all facts and all natural laws and within which every fact and every law has relations exact, defined and permanent. It is for the scientific investigator to reap, in this unbounded harvest field, just as extensively as his own finite powers give him means and opportunity, leaving to later generations of followers a clean and wellgleaned field as far as he may be permitted to go.

\section{IX.}

The building of a science is admirably illustrated by the work of Rankine and of Clausius, supplemented in details by Kelvin, Zeuner, Röntgen, Hirm and the later investigators and students of the outlined science.
Rumford and Davy, Meyer, and Joule, supplied the numerical value of the factor relating the recognized thermal and dynamic energies, and the identity of these energies in their essential nature, suspected by the ancients, had been sufficiently proved by the first named. Rankine made his foundation the two principles:

1. Heat and mechanical energy are interconvertible and with a definite quantivalence.

2. Any single effect of the action of thermal energy is proportioned definitely to the quantity of such energy present and acting in the production of the phenomenon.

Clausius made his fundamental propositions :

1. The thermal and dynamic energies have a definite and measured quantivalence.

2. It is impossible for a self-acting machine to derive mechanical energy by transfer of heat from a body of lower temperature to one of a higher temperature.

The latter principle is variously stated by these authors and still differently by others; but the deductions are the same whatever the verbiage. The one principle states the quantivalence of the energies; the other gives a means of determining what amount of energy, under specified conditions, shall be transformed, at the quantivalence stated, from one to another class. The first permits the immediate construction of the algebraic expression of the law :

Such mechanical energy as is transformed in any case has the measure: heat-energy in thermal units multiplied by Joule's equivalent. This is universally recognized as 'the first law of thermodynamics.'

The second statement leads, directly or indirectly, to the expression of the algebraic relations of work transformed out of heat, or the reverse, to total energy expended in the process studied; the work obtained by 
transformation of thermal into dynamic energy in any defined case is measured by the product of the rate of variation of work with temperature into the measure of the absolute temperature at which the observation or the computation is assumed to be rade. If the work-effect is exhibited in change of temperature, in change of volume at constant temperature, or by any single phenomenon in energetics, the formula will $\mathrm{l}$ ave the same form.

$i$ is now easily practicable to obtain the fundamental equation of the science of thermodynamics.

Thus, on two simple propositions, based upon scientific deductions from observations of natural phenomena, and with the facts obtained by scientific research regarding specific heats, volumes, pressures and tensions, the whole great and wonderfully important and productive science of thermodynamies was by these two men of genius, independently and with entire originality, constructed, and their results were published practically and simultaneously. Had it been possible to measure the internal forces of the non-gaseous substances, this important science might have been constructed upon the basis of the first law alone. It is not at all certain that it may not yet prove practicable to eliminate the second law as an essential primary proposition; means being discovered of reducing the perfect gas and the vapor, the liquid and the solid, to a common form of analytical expression involving the four fundamental factors. The one now impassable obstruction to this simplification of the science is our inability to measure internal forces and to discover. their law of variation.

Since Thomson has discovered evidence of the possibility of the divisibility of the once supposedly indivisible atom, and since the employment of the electric forces in the analysis and synthesis of substance in every form, even the production of a new science, remains apparently among the opportunities and in the future, perhaps, many new sciences. The reduction to measure and to law of Thomson's 'corpuscles' may prove to be the first step toward the solution of many remaining problems otherwise beyond our, powers of analysis. This new fact, if it so prove, may reveal to us the real nature of the luminiferous ether, already studied by Herschel, by Wood and others.

The extraordinarily interesting and wonderfully ingenious investigation of the thermodynamics of the luminiferous ether, made by De Volson Wood, in 1885 or earlier, which study, however, seems to have attracted little attention as yet, admirably illustrates the fact that, given a certain definitely known system of facts and principles, a single thought of the man of genius may open a new and wonderful vista to the mind of man.*

The essential properties of every 'perfect gas' had long been known. It was known that two essential physical characteristics of the ether had been determined quantitatively - the velocity with which energy was transmitted by its vibrations and the quantity of energy transmitted by it from the sun to the earth per unit of its section. It transmits energy at the rate of 186,300 miles, 982,000,000 feet per second. (299,838 kilometers per second), and delivers heat energy from the sun at the rate of about 2.8 calories per square centimeter of the section of the beam, 133 foot-pounds per square foot, per second.

Taking the evidence as wholly in favor of the conclusion that the luminiferous ether is a perfect gas, if a perfect gas in the thermodynamic sense exists at all, Wood

* 'The Luminiferous Ether,' by De Volson Wood, Philosophical Magazine, November, 1885; Van Nostrand's Magazine, January, 1886; Wood's 'Thermodynamics,' Appendix I. 
shows that what he denominates the 'modulus of the gas,' the product of two measurable factors for all gases, is a constant, Wood finds no difficulty in determining the physical characteristics defining such an ether with at least approximate accuracy. He finds them, as would naturally be expected, most extraordinary, as must needs be in a gas transmitting vibrations at the rate of nearly two hundred thousand miles a second. His conclusions are thus expressed:

A medium which has density such that a volume of it is equal to about twenty volumes of the earth would weigh one pound; whose tension is about 1.1 pound on the square mile; whose specific heat is $46 \times 10^{11}$, water being unity - would 'satisfy the requirements of nature, in respect to transmission of heat-energy and light. This conclusion from facts of observation and a probable theory differs from Herschel's result in giving a high value of specific heat, rather than of tension; substituting a more probable for an entirely improbable conclusion. This extraordinary but always essential element of the universe, it is found, must have a practically uniform tension and density throughout space, changing little between the surface of a star and the depths of infinity. It at once follows, we further conclude from Wood's data, that if the ether be of limited quantity, at a finite distance from the center of attraction of the universe it must have a definite limit, as of a fog-bank, out of which no ray of light and no stream of heat-energy can pass to other worlds. From Wood's striking yet simple analysis we may derive thus the conclusion that, should it prove correct, there may exist other universes than ours, from which no heat or light or other ethereal messenger may come to us, but yet that it is possible that, some day, two universes may come together, to unite as one or, in inconceivable violence of world-collision, to disperse into a single nebula, subsequently to condense again into a single universe. A runaway star from outer space may unexpectedly appear to cause similar results.

At the height of 127 miles, the atmosphere would have the density of such an ether, and this constitutes a measure of the altitude of the atmosphere in close accordance with a variety of other determinations on other and different bases. Everywhere the ether is practically diathermous, nonresisting, and constant in all physical properties.

An assumption made by Wood was that of the temperature of space, taken by him at $20^{\circ} \mathrm{F} .\left(11.1^{\circ}\right.$ C.) above absolute zero, not far from the temperature of solidification of hydrogen. But no important change that could be accepted as consistent with our knowledge of the temperature of the interstellar space would greatly alter the conclusions reached; nor, in fact, would any probable admissable assumption of an independent measure of the 'modulus' of this wonderful gas. It is, however, probable that this intensely seductive case is not yet closed.

X.

The opportunities of the investigator and of the collaborator are beyond our recognition, and probably, in our present state of incomplete evolution, even our conception. They may certainly be expected to furnish problems, indefinitely, for research in all fields and for all the immediate future of science. The resolution of all the recognized sciences, and of possibly as yet unclassified or even unsuspected sciences, into one great system is a final problem to be approximated with the passage of the centuries.

That such an unlimited range is permitted in the work of the man of science is easily seen. In the first place, man, from the beginnings of scientific study and in- 
vestigation, has steadily advanced into the unknown; secondly, his progress has been an acceleration which has been increasing in its rate from the beginning; thirdly, all progress has been made by a continuity of path which indicates no limit to its reach; finally, we know that the various fields of scientific work are all exhibiting, as far as we have gone, a perfect continuity. It would seem most probable, if not absolutely certain, that, once we have secured a foothold upon any new field, we may anticipate complete ultimate exploration. Once we have gained firm hold upon any one link in the logical chain of law controlling any class of phenomena, we may expect to be able, in due time, to pass, link by link, to either end, or, if endless, either through its cyclical configuration or indefinitely towards its infinity of development, and to gain as much of its length as finite time may permit. So much may we prophesy.

It is also true that scientific investigation and general observation show that the process of scientific deduction is always as simple and as direct as a child's logic. It necessarily depends upon the following of a chain of reasoning, based upon interlinked, ascertained, facts, every step from link to link of which is an axiomatic deduction. This is true of all reasoning, and in no department of human knowledge or investigation is this a more absolute and imperative general condition of assurance of certainty of results than in each step in scientific research.

When it was first observed that the glowworms and the fire-flies produced a light within their own bodies, it became an axiomatic inference that it was a 'cold light' and that it could not be accompanied by any heat of higher temperature than that of the cold-blooded creature from which it emanated. When Langley proved by means of his bolometer that the light of the fire-fly, instead of producing a candle-temperature of $2000^{\circ} \mathrm{Fahr}$. (above $1100^{\circ}$ C.) was quite free from sensible heat, it became obvious that this must be the 'cheapest form of light' and that, could we find a way of imitating nature in this direction, instead of wasting 99 per cent. or more of our expended energy, as in the ordinary gas-flame, we might secure nearly a hundred times as much light from the same cost in energy supplied, and thus practically without waste.* As stated by Langley and Very, this light 'is a result of certain chemical combinations and nothing forbids us to suppose that it may some day be produced by the processes of the laboratory.' Perhaps we may go further and say that, as a product of a chemical process, it may prove to be possible to reproduce it by the direct application of the elementary energies which there operate. This is one of the great problems still challenging the chemist, the electrician and the engineer. It will be solved when we learn to produce any part of the spectrum, heat and light in any proportion, from zero to unity, at will.

Nature's 'cheapest light,' according to Langley and Very, involves heat-production about one four-hundredth that of the candle-flame and has an insignificant cost, so measured, as compared with the most economical light yet employed for industrial purposes by man. Nature produces light and almost no heat; man produces light with a hundred times as much energy wasted in form of accompanying heat, even with his best lights. Nature, through an evolution extending over countless centuries, millenniums, probably, has brought about the perfection of energy-utilization. Man, guided by nature, should be able, in

* S. P. Langley and F. W. Very, 'Cheapest Form of Light,' Smithsonian Coll., XLI., 1901. S. P. Langley, ScIence, June 1, 1883; Proc. National Academy. President's Inaugural, Am. Soc. Mech. Engrs., 1880, R. H. Thurston. 
a comparatively brief period, to reach the same end. Nature causes to conspire all the energies and all the forces with all the materials of creation in the production of her purposes with most perfect efficiency. Man should be able, studying her ways, to do the same. Nature makes all the universes obey her single law. Man should be able to not only detect, define and reduce to rule and measure that universal law, but he should be able to compel the universal law to his service and to produce as complete and consistent a world of his own-so far as it goes, at least-as is exemplified in the natural world about him. Directing every energy precisely to the accomplishment of its prescribed purpose, applying every substance in its right place and in the right manner in his constructions, and bending every law to his aid in the building of a world, he may profit in maximum degree by every force, energy and substance, by all material and all spiritual laws and phenomena, by all opportunities of advancing himself to loftier and loftier planes, perfecting himself and perfecting life by continuous gain.

The solidification of hydrogen by Professor Dewar, April 6, 1900, before the Royal Institution, brought us, at the beginning of the twentieth century, to the conclusion of a series of brilliant researches which had for their outcome evidence that all known forms of elementary matter, are capable of assuming either of the three principal states, gaseous, liquid or solid, to this degree reducing all matter to common rules and an all-comprehending law. It now only remains to ascertain whether, as De Volson Wood assumed, the luminiferous ether, perhaps 'corpuscular,' may be classed with the more ponderable forms of matter. This seems possible, even probable. This series of investigations of the effect of low temperature upon the elements completes that line of study, and it will presumably, ere long, be seen that this, like every other great victory over nature in the domain of pure science, will have its ultimate and practical value as well in the opening of the way to other, and perhaps no less splendid, researches, as in the introduction of new methods of application of the forces of nature to the use of man.

The recent and richly fruitful discovery of the so-called 'radio-activity' of certain forms of matter brings forward new facts of quite another class and provokes the investigator into new fields of research. This mobility of energy, or matter, whichever it may prove, taken together with the Roberts-Austen proof of the mobility of solids and their interflow, even the densest of them all, opens the way to the application of a new form of theory of glacierlike flow in the field of metallurgy, and possibly with even more widely reaching employment. Perhaps it may align itself with the current theory of electric ionization.

A wonderfully simple experiment will sometimes result in a no less wonderfully important deduction. When Roberts-Austen placed lead and gold in contact, fitting their adjacent surfaces nicely to insure perfect contact, and later found that molecules of gold had started off on a journey, independently, into the lead, some of them reaching a distance from their original positions of two inches in as many years, that simple test was sufficient to prove the propositions that alloys may be formed without heat or fusion, that glacial flow is not characteristic of the glacier alone, that osmose in solids may occur as in liquids and in gases, only requiring a longer time for its accomplishment, and that new industries may perhaps be organized on this simple basis of fact. The conclusion, enormous in its scientific importance, unimaginable in its extent of deduction, may be drawn from this one experiment, accord- 
ing to Rücker, that all matter is atomic in plan, that it 'consists of discrete parts capable of independent motions,' * that the atomic theory has a basis of fact. This conclusion is regarded as positive and necessary, whatever the characteristics of those parts may prove to be. Such simple facts probably led Lord Kelvin to conclude, as he wrote to Professor Holman, "we may expect the time to come when we may understand the nature of the atom. With great regret I abandon the idea that a mere configuration of motion suffices.' +

Wiedemann's deduction from his study of the light from sodium vapor and incandescent platinum, that the energy needed for producing 'pendulous movement' of atoms or molecules giving light-effects must be very insignificant in comparison with the total energy employed, may throw some light both on this question and on that relating to the 'cheapest form of light.'

It is by this scientific method of gradual revelation of the secrets of nature and this foresight of the coming knowledge, this discovery of methods and this apprehension of the continuity of law, that the chemist has come to such perfection in the analysis of all known substances and in the synthesis of many valuable and useful compounds; as in his production of all the coaltar products, in the reinforcement of nature in the production of artificial madder and increasingly numerous lists of other materials of commerce. It is through this art of revelation and of prophecy that the physicist has shown the way to the engineer in the utilization of electrical energy and the distribution of light, power and intelligence, and has given the astronomer the means of analysis of the most distant stars and measurement of their rate of approach or recession. Thus the geologist

\footnotetext{
* President's address before the British Association for the Advancement of Science, 1901.

† Science, June 22, 1900, p. 988, E. H. Hall.
}

learns the history of the earth, the lesson of its construction and the tale of a coming time of progressive decline in all its forms of life, and even roughly computes the past and the future period of its life, from superheated to a cold and dead estate. The building of a science gives progress to civilization, reinforces real learning and advances the individual man to higher life.* R. H. Thurston.

\section{Cornell University.}

$$
\text { (To be continued.) }
$$

\section{ON SOME RECENT ADVANCES IN THE FIRE- PROOFING TREATMENT OF WOOD. $†$}

THE saturation of wood with chemical solutions has mainly two objects in view, either to prolong the life of the wood by rendering it as resistant as possible to decay, or to make it resistant to the attack of fire and to cause it when exposed to flame to carbonize as slowly as possible without, of or from itself, contributing to the increase of the flame. We will take up the second of these two lines of treatment for. present discussion.

The treatment of wood with a view of making it fire-resistant is not a matter of

* The use of the 'curve of progress' sometimes finds curious and unexpected application. The study of the curve of progress of the speed of the horse was years ago attempted by this method, and it was found by the author of this address that the 'two-minute horse' might be expected at about the commencement of the twentieth century. Several periods of smooth progress, broken, ' catastrophically,' by improvements or by inventions, were observed, as when the four-wheeled 'wagon' was superseded by the 'sulky' and when the pneumatic tire was introduced. In each curve the trend has, at the break, become approximately asymptotic. The horse had nearly reached his limit and the reduction of load was the only recourse, in further promotion of progress.-Sci. American Supplement, December 1, 1894.

$\uparrow$ Read before Section C of the American Association for the Advancement of Science, Pittsburgh meeting, June, 1902. 